\title{
APUNTES SOBRE EL CONCEPTISMO SACRO EN ALGUNOS VILLANCICOS DE JOAN PAU PUJOL $\left({ }^{*} 1570\right.$ - †1626)
}

\author{
MARIANO LAMBEA \\ Departamento de Musicología, CSIC.
}

Barcelona

Para Lola

\section{A GUISA DE PRÓLOGO}

Estudiar y trabar conocimiento de las motivaciones, aspiraciones e inquietudes espirituales e intelectuales de la cultura de la época barroca es tema apasionante. Sus creaciones artísticas en los diferentes ámbitos de las bellas artes, su literatura y su música han conseguido que esta época crucial del pensamiento en la cultura y el arte de la civilización occidental justifique su valor por sí misma, y rechace, a través de sus grandes ingenios y sus obras cimeras, la letanía de tópicos peyorativos que la historiografía posterior, por diversos frentes, le ha aplicado, en lo que se refiere a corruptora del gusto y equilibrio clásicos. En efecto, el Barroco ha resistido perfectamente la crítica de cuño racionalista en su pretensión de desprestigio sistemático. Y, ahora, he aquí el interés intelectual que suscita a los estudiosos y el placer estético que seduce a los espíritus sensibles. Este entramado de intelectualidad y espiritualidad, máximo exponente de la mentalidad barroca por las mutuas y complejas interrelaciones que contiene, hace posible que muchas veces el investigador o historiador actual tome consciencia de que su labor no debe estar dirigida en un sentido unívoco, lo cual le daría una visión parcial de la realidad que estudia, sino que ha de optar por una vía de conocimiento integradora que aglutine diversos aspectos de una misma realidad que, en ocasiones, puede mostrársele esquiva a la aprehensión, además de cambiante, caleidoscópica o caprichosa.

En este sentido, el concepto de interdisciplinareidad como vía de conocimiento del Barroco adquiere aquí capital importancia, ya que permite 
abordar estudios serios, es decir, estudios que intentan aproximarnos a la verdad. Creo que la aplicación interdisciplinaria al análisis histórico de las mentalidades en épocas de fuerte espiritualidad, como es la del Barroco, resulta imprescindible, sobre todo, si tenemos en cuenta que en este período las artes, las letras y la actividad cultural del hombre están cohesionadas, principalmente y de manera casi exclusiva, por un motivo vertebrador de amplia penetración social y psicológica como es, en este caso, la religión. Quiero decir con ello que ante un elemento unificador de necesidad cotidiana que afecta la vida toda, y otorga sentido y contenido a cualquier manifestación artística y cultural, se impone estudiar ese complejo entramado de relaciones con una metodología también de signo unificador, como es la interdisciplinaria que refiero.

En nuestro país, el saludable interés en realizar trabajos de carácter interdisciplinario entre música y literatura data de un tiempo relativamente reciente $^{1}$. La declaración de intenciones - que siempre ha estado implícita- entre los estudiosos de ambas ramas del saber, en el sentido de poner definitivamente hilo a la aguja, se ha quedado más en el campo de la teoría que en la resolución práctica, salvo raras excepciones. Es posible que las dificultades en iniciar el auténtico proceso de enriquecimiento mutuo se hagan patentes en la preparación académica respectiva de filólogos y musicólogos, sobre todo en lo que se refiere a planes de estudios en las universidades españolas, ya que al no contemplarse en ellos la obligatoriedad de cursar asignaturas complementarias de ambas carreras, sucede que el musicólogo sabe poco de literatura y el filólogo menos aún de musicología. La solución pasa, pues, o por el cauce del autodidactismo y de la culminación de las propias inquietudes intelectuales de cada investigador en particular, o por la opción de trabajar en equipo, lo cual no deja de ser casi utópico en los tiempos de competitividad que corren hoy en día, y que afectan también a las humanidades y ciencias históricas. Por mi parte, prefiero la formación integral del investigador, aunque sea a costa de duplicar esfuerzos, porque la compensación es altamente satisfactoria. Creo que a los musicólogos nos debe interesar muchísimo saber algo de literatura, en especial si se estudia un período como el Barroco en el que decurso vital y ficción literaria van indisolublemente unidas.

1 Más recientemente aún, y por lo que se refiere a la época barroca en concreto, la Facultad de Filosofía y Letras de la Universidad de Valladolid organizó un Congreso Internacional dedicado al tema, con aportaciones de diversa índole a cargo de grandes especialistas en filología y musicología. Vid. al respecto el volumen Música y Literatura en la Península Ibérica: 1600-1750, Actas del Congreso Internacional (Valladolid, 20-21 y 22 de febrero de 1995), edición a cargo de María Antonia VIRGILI BLANQUET, Germán Vega GARCÍA-LuENGOS y Carmelo CABALlERo FernáNDEZ-RuFETE, Valladolid, V Centenario Tratado de Tordesillas, 1997. 


\section{OBJETIVOS Y METODOLOGÍA}

El objetivo del presente trabajo se centra en observar los rasgos fundamentales del estilo literario denominado «conceptismo sacro», en los textos anónimos de algunos villancicos puestos en música por el compositor mataronés Joan Pau Pujol $(* 1570$ - †1626) y confrontarlos con textos de poetas como el segoviano Alonso de Ledesma y Buitrago $\left({ }^{*} c .1562-\nmid 1633\right)$ o el toledano José de Valdivielso $(* 1560$ - $\uparrow 1638)$, gran amigo de Lope. Habrá que tener presente, por otra parte, algunos postulados de la obra cumbre de la estética conceptista, como es la Agudeza y arte de ingenio del escritor jesuita Baltasar Gracián $(* 1601$ - $† 1658)$.

Por conceptismo sacro entiendo el estilo literario conceptista aplicado tanto a la poesía religiosa o sagrada en sí, como a la poesía profana o humana remedada, vuelta o contrahecha a lo divino. Para la espiritualidad y mentalidad de la época barroca era necesario que hubiera un obstáculo, por mínimo que fuera, que dificultara la aprehensión intelectual, porque se tenía la seguridad de que lo que fácilmente se aprendía, más fácilmente se podía llegar a olvidar. Precisamente, en ese obstáculo (el cual, desde nuestro punto de vista, unas veces es pequeño, otras grande y aún otras inmenso e insalvable) tropezamos los que investigamos estos temas sin ser filólogos o historiadores de la literatura, ya que, en numerosas ocasiones, no sabemos lo que quieren decir con exactitud algunos versos determinados, entre otras cosas - sospecho-, porque no estamos imbuidos del espíritu de la época y no comprendemos sus tópicos poéticos, sus «lugares comunes» y los convencionalismos lingüísticos que hacían de ese lenguaje poético algo perfectamente comprensible a sus coetáneos aunque fueran, como eran muchos de ellos, analfabetos. Ese obstáculo al que me refiero no es otra cosa más que el «concepto», entendido ampliamente para que pueda albergar en su significado todo un abanico de posibilidades sobre el pensamiento analógico (alegorías, metáforas, simbolismo, correspondencias, etc.) tan característico del comportamiento y sentimiento barrocos.

Baltasar Gracián, en su Agudeza... (1642) ${ }^{2}$, expone y desarrolla todo un auténtico tratado sobre el conceptismo, y algunos de sus sesenta y tres discursos tienen su perfecta aplicación a los villancicos del maestro catalán que he estudiado, así como a diversos autos sacramentales que he leído, en cuyos textos he observado que no siempre se dicen las verdades teologales o dogmáticas de una manera clara y tajante, sino velada e inge-

2 Vid. Ricardo del ARCo, «Baltasar Gracián y los escritores conceptistas del siglo XVII», en Historia general de las literaturas hispánicas, publicada bajo la dirección de D. Guillermo DíAZ PLAJA, con una introducción de D. Ramón MENÉNDEZ PIDAL, vol. III «Renacimiento y Barroco», Barcelona, Editorial Barna, S.A., 1953, pp. 693-726; especialmente, las pp. 709-711, que están dedicadas a la Agudeza y arte de ingenio. 
niosa. Por otra parte, la diferencia de años entre la composición de los villancicos de Pujol (1612-1626) ${ }^{3}$ y la publicación del libro de Gracián (1642) no es óbice para poder aplicar con tranquilidad y seguridad los contenidos y matices de la obra del escritor aragonés a las poesías que me ocupan, ya que sus aportaciones sobre el conceptismo representarían el punto culminante de un proceso anterior perfectamente asimilado desde poetas como el ya citado Alonso de Ledesma ${ }^{4}$, contemporáneo verdaderamente de Pujol, que publicó una obra titulada, precisamente, Conceptos Espirituales y Morales, entre 1600 y $1612^{5}$. Durante medio siglo, hasta 1660 , esta obra, que está dividida en tres «Partes», se editó en diversas ciudades de la Península Ibérica como Alcalá de Henares, Barcelona, Lérida, Lisboa, Madrid y Valladolid ${ }^{6}$. Es importante constatar que, por lo que respecta a Cataluña, los Conceptos de Ledesma vieron la luz pública en las siguientes ediciones:

Primera parte (Barcelona, 1603, 1604, 1605, 1606, 1607 [2 eds.], 1612 y 1613; Lérida, 1612) ${ }^{7}$.

Segunda parte (Barcelona, 1607 [2 eds.] ${ }^{8}$.

Tercera parte (Lérida, 1612) ${ }^{9}$.

Volviendo a Gracián, vale la pena citar algunos de los discursos que se refieren a la dificultad de aprehensión del contenido poético, debido al uso del concepto que consigue enmascarar la evidencia; las citas vienen en la edición del Romancero espiritual de Valdivielso, a cargo de J. M. Aguirre:

3 Fechas perfectamente documentadas en mi tesis doctoral Los villancicos de Joan Pau Pujol (*1570 - +1626). Contribución al estudio del villancico en Cataluña, en el primer tercio del siglo XVII, [Edición en microficha] volumen I (Estudio), Bellaterra, Publicacions de la Universitat Autònoma de Barcelona, 1999, pp. 26-27.

4 Vid. Ricardo del ARCo, «Escritores conceptistas del siglo XVII. Precedentes. Alonso de Ledesma y Buitrago. Alonso de Bonilla», en op. cit., pp. 713-715.

5 Vid. Alonso de LEDESMA, Conceptos Espirituales y Morales, edición, introducción y notas de Eduardo JULIÁ MARTíneZ (Biblioteca de Antiguos Libros Hispánicos, A, XXVII, XXVIII y XXIX), Madrid, Consejo Superior de Investigaciones Científicas, Instituto «Miguel de Cervantes», 1969, tres vols. correspondientes a las «Partes» Primera, Segunda y Tercera.

6 Vid. José Simón DíAz, Bibliografía de la literatura hispánica, Madrid, Consejo Superior de Investigaciones Científicas, Instituto «Miguel de Cervantes» de Filología Hispánica, 1984, Tomo XIII, pp. 8a-27a, 50-83. Como puede observarse, algunas de estas ediciones se han perdido, pero de la inmensa mayoría de ellas se conservan ejemplares en diversas bibliotecas españolas y extranjeras.

7 Ibídem, pp. 14a-15a, n. ${ }^{\text {s }} 53,55,57,58,59,60,64,65$ y 66.

8 Ibídem, pp. 15b-21a, n. ${ }^{\text {os }} 76$ y 77.

$9 \quad$ Ibídem, p. 26b, n. ${ }^{\circ} 82$. 
Discurso LXI: «La desnuda narración es como el canto llano: sobre él se echa después el agradable artificioso contrapunto» ${ }^{10}$.

Discurso VII: «La verdad, cuanto más dificultosa, es más agradable, y el conocimiento que cuesta, es más estimado» ${ }^{11}$.

El ámbito de aplicación de la idea de concepto pasa por la analogía. El pensamiento y el sentir barrocos son analógicos por antonomasia en su tendencia a establecer relaciones de semejanza entre cosas que son realmente diferentes, y aún dispares. El concepto, como impedimento intelectual a la verdad, para que no sea demasiado evidente y demasiado rápida en manifestarse, es el primer y más importante aliado que tiene la analogía. También se puede argumentar que el concepto es una especie de velo antepuesto a la realidad con vistas a hacerla didácticamente más sugestiva y más atractiva ${ }^{12}$. Leyendo los textos de los villancicos de Pujol puede observarse lo que acabo de decir, especialmente en algunos de ellos. Pondré un par de ejemplos de muestra para ilustrar lo que digo con la esperanza de errar lo menos posible; se trata de dos villancicos de temática eucarística:

El primero lleva por título Amor pone cerco a $\operatorname{Dios}^{13}$ (Fig. 1 y Fig. 2):

\title{
[ESTRIBILLO]
}

\author{
Amor pone cerco a Dios, \\ no se le irá por los pies. \\ Preso está, cogido es, \\ alma mía, para vos.
}

\section{COPLA $1 .^{\mathrm{a}}$}

Una blanca torre tiene
por cárcel donde estará.
La patente pagará
con un convite solenne,
que el carcelaje de Dios
para el mundo dé interés.
Preso está, cogido es,
alma mía, para vos.

10 Vid. José de VAldivielso, Romancero espiritual, edición, introducción y notas de J. M. AGUIRRE, Clásicos Castellanos, 228, Madrid, Espasa-Calpe, 1984, p. LXI de la «Introducción».

11 Ibídem, p. LXXII.

12 A propósito de ello es muy interesante el libro de Roland BARTHES, El placer del texto, Buenos Aires, Siglo XXI Argentina, 1974, (1. ${ }^{a}$ ed. española), fundamentado en la importancia que tiene en el arte literario la idea de velarle al lector el pensamiento que se esconde detrás de toda obra.

13 Biblioteca de Catalunya, Sign.: M. 749/2. Se trata de un villancico a solo, 3 y 4 voces. Autor de la música: Joan Pujol. 


\section{COPLA $2 .^{\mathrm{a}}$}

Pues rinde su voluntad

al Amor con tanto exceso, visitemos este preso, que es obra de caridad, que prisión donde está Dios, paraíso y cielo es.

Preso está, cogido es, alma mía, para vos.

[ESTRIBILLO]: el «cerco» que Amor (asimilado a Cupido, pero con intenciones místicas, evidentemente) pone a Dios hace referencia a la forma circular de la Hostia, en una primera lectura. El concepto hay que observarlo en una segunda lectura, donde vemos que el cerco limita y consecuentemente resalta la idea de prendimiento que conduce a la otra idea posterior de mayor profundidád como es la de inmolación o sacrificio; todo ello en beneficio de la salvación del alma del hombre pecador. Este amor, impregnado de intención divina y nunca terrena, es aquí un aliado o benefactor del alma y se presta siempre a ayudarla espiritualmente.

Copla $1 .^{\text {a: }}$ las alegorías del estribillo se hallan aquí también, pero con otras imágenes. La «blanca torre» es, naturalmente, la Hostia. La «patente» ${ }^{15}$ es algo similar a lo que en nuestros días entendemos por novatada, y en este caso vendría a ser la nueva vida que Jesús estrena en la tierra cuando es enviado por el Padre. El pago de la patente es la pasión y muerte que ofrece después por nuestra redención. El «convite» es, evidentemente, la Santa Cena. La «cárcel» que el Padre impone al Hijo es la sagrada forma

14 La puntuación y demás aspectos filológicos de los villancicos y romances sacros de Pujol han sido realizados por el Dr. Josep Romeu Figueras, a quien agradezco sinceramente su amabilidad y disposición en estos aspectos del trabajo.

15 No hallo la palabra «Patente» en Sebastián de CovARrubias, Tesoro de la Lengua Castellana o Española, según la impresión de 1611, con las adiciones de Benito Remigio Noydens publicadas en la de 1674, edición preparada por Martín de RIQUER, Barcelona, S. A. Horta, I. E., 1943. Entre las varias acepciones de la voz «Patente» que da la Real Academia Española, en su Diccionario de Autoridades (Biblioteca Románica Hispánica, V. Diccionarios, 3), (edición facsímil del Diccionario de la lengua castellana..., Madrid, Imprenta de la Real Academia Española, 1737), Madrid, Editorial Gredos, 1976, 3 vols. (3. ${ }^{a}$ reimpr.), vol. 3, p. 162b de la primera numeración, creo que la más adecuada para mi trabajo es la siguiente: «PATENTE. Significa assimismo la contribución que hacen pagar por estilo, los más antiguos al que entra de nuevo en algún empleo u ocupación. Es común entre los estudiantes en las universidades, y de ahí se extendió a otras cosas.» A continuación viene el siguiente ejemplo, extraído de Las Musas de Quevedo:

«Sobre el pagar la patente,

nos venimos a encontrar

yo y Perotudo el de Burgos,

y acabóse la amistad.» 
$\mathrm{y}$, sin duda, el «carcelaje» ${ }^{16}$ (una especie de impuesto o arbitrio) es de mucho «interés» para la humanidad, ya que representa su salvación.

Copla 2. : creo que no hay nada nuevo que comentar aquí; únicamente la belleza de la metáfora que equipara el acto de la Comunión a la visita humanitaria que se debe rendir a un «preso» como es Jesús sacramentado.

En este villancico se observa una continua analogía entre cualquier prisión o cárcel terrenal, que invita a pensar siempre en un lugar inhóspito, privado de alegría y felicidad, y oscuro como mazmorra, y la Hostia consagrada que, aunque en el fondo sea lo contrario, pues es «una blanca torre» e, incluso, «paraíso y cielo», realmente no deja de ser también otra prisión, o, al menos, un lugar pequeño, un simple trozo de pan, en el que Dios eterno permanece encerrado. Vemos, pues, la relación de semejanza a partir de diferencias manifiestas; estas últimas resultan evidentes a los sentidos, pero albergan relaciones de afinidad conceptual. Por otra parte, el concepto vendría a contener tanto la dificultad que se ha de vencer para penetrar la lectura del villancico, como el ingenio mostrado por el poeta en escribirlo.

El segundo de los villancicos se titula Al blanco, que está Dios alli ${ }^{17}$ (Fig. 3 y Fig. 4):

\section{[ESTRIBILLO]}

-iAl blanco, al blanco, que está

Dios allí! - Nadie lo ve.

- Tira, que sin ver la fe

de medio en medio le da.

\section{[COPLA $\left.1 . .^{\mathrm{a}}\right]$}

-iAl blanco, al blanco, flechero!

Que ya para ser tu blanco, detrás dese velo blanco

se encierra Dios verdadero.

-A Dios y a ventura va.

y a Dios sin duda daré.

-Tira, que sin ver la fe

de medio en medio le da.

16 Tampoco viene la palabra «Carcelaje» en el Tesoro... de Covarrubias. En el Diccionario de Autoridades, vol. 1, p. $164 \mathrm{~b}$ de la segunda numeración, consta una definición de «CARCELAGE» que creo que es la adecuada para el sentido de este villancico: «El derecho que pagan los que están presos al salir de la cárcel, por la custodia que se tuvo de sus personas.»

17 Biblioteca de Catalunya, Sign.: M. 749/14. Se trata de un villancico a 6 voces, divididas en dos coros. Autor de la música: Joan Pujol. 
[COPLA 2. ${ }^{a}$ ]
-Antes no viendo va bien el tiro a Dios y a ventura, que dando en Dios asegura nuestra ventura tan bien. -Pues, como con Dios está, sin duda la alcanzaré. -Tira, que sin ver la fe de medio en medio le da.

En este villancico, el poeta parte de una situación de la vida real, como puede ser una cacería o un pasatiempo para practicar la puntería, y, desde ahí, construye una alegoría en la que el «blanco» es la sagrada forma. Seguramente el concepto radica en la analogía del blanco como diana y del blanco como color de la Hostia.

Además, creo que puede haber otra lectura que se relacionaría con la ingeniosidad del concepto, en cuanto a que, en realidad, la auténtica idea que aquí subyace es la de acertar en un blanco que no está al alcance de cualquiera, sino sólo de aquel que tenga «fe» en ver aquello que no se ve, o que está oculto detrás de un «velo», asimismo, de color blanco. Puede decirse, pues, que el tema fundamental de este villancico gira en torno a la idea principal de la fe, del fideísmo ${ }^{18}$, tema muy del gusto de la mentalidad contrarreformista, e ideal para defender el dogma de la eucaristía ante la posición luterana. En este sentido, con la ayuda de la fe, pues, el que acertara a dar en el blanco, en realidad, es posible que estuviera acertando en descubrir a Dios. A propósito del dogma de la fe citaré unos párrafos de J. M. Aguirre que son muy interesantes por las agudas observaciones que contienen sobre las poesías del Romancero... del maestro Valdivielso:

«El poeta del pueblo [Valdivielso] se da cuenta de la gran dificultad que entraña la enseñanza de los dogmas del cristianismo, a la vez que se siente en la obligación de poner al alcance de la gente sencilla los fundamentos teológicos de su fe.[...]

»Ante el misterio de la presencia real de Cristo en el Sacramento de la Eucaristía, el poeta hace hincapié en la importancia y la necesidad de la fe. El argumento [de un villancico que Aguirre incluye como ejemplo, pero que no es necesario transcribir aquí] está tomado del himno de Santo Tomás de Aquino, «Lauda Sion»:

18 Vid. José Ferrater MORA, Diccionario de filosofía, Madrid, Alianza Editorial, 1979, vol. II, p. 1170b: «FIDEÍSMO se llama generalmente a la doctrina que sostiene la impotencia de la razón para alcanzar ciertas verdades y la consiguiente necesidad de introducción de la fe. Este sentido no coincide con el que tiene para la Iglesia católica, en donde representa una tesis teológica que admite una facultad especial determinada por la fe y destinada a la interpretación de los misterios.» 
Quod non capis, quod non vides, animosa firmat fides praeter rerum ordinem.[... $]^{19}$

»Y con estos ejemplos, estamos otra vez ante la sutileza poética de Valdivielso, su agudeza para mantener en equilibrio la abstracción teológica y, en este caso, el realismo lingüístico en que son expresados los dogmas» ${ }^{20}$.

Volviendo al argumento de tirar al blanco, uno de los romances incluido por Alonso de Ledesma en la tercera parte de sus Conceptos..., hace referencia también al tema del tiro al blanco, y precisamente está subtitulado «en metáfora de tirar al blanco.» El romance no es excesivamente extenso, y vale la pena copiarlo en su integridad para observar las similitudes argumentales con el villancico que musicó Pujol, y del cual ignoro el autor del texto. Téngase en cuenta que el significado de algunos versos de Ledesma viene explicado o aclarado en nota a pie de página mediante las correspondientes apostillas. Por esta razón, antes del texto del romance, voy a transcribir unas frases muy interesantes de Ricardo del Arco sobre Ledesma, el concepto, los subtítulos y las apostillas «explicadas al margen»:

«En los conceptistas predomina el vigor del concepto, la ingeniosidad, la expresión retorcida, la antítesis, la oposición de dos conceptos, y la metáfora, a veces tratada con desgaire culterano. En las poesías predomina el tono menor, el verso corto octosílabo y hexasílabo, la endecha y el villancico. Así Ledesma, que se distingue especialmente por la oposición de conceptos o de imágenes como tema conductor. Claramente indican su contextura los subtítulos de algunas composiciones («en metáfora de un reformador de una Universidad», «en metáfora de guerra», «en metáfora de una fragua», etc.). Estas metáforas constituyen precisamente el «concepto», en algunos casos explicadas al margen de la composición. Tiene Ledesma romances, endechas, canciones cortas y villancicos $[\ldots]{ }^{21}$.

Y ahora el romance de Alonso de Ledesma que transcribo íntegramente, numerando las estrofas entre corchetes y respetando los criterios ortográficos, puntuación y acentuación del editor moderno, Eduardo Juliá Martínez, así como las apostillas ${ }^{22}$ que vienen a pie de página, excepto las

19 Vid. J[ohn] J[ULIAN]: «Lauda Sion Salvatorem» en A Dictionary of Hymnology, Edited by John Julian, D.D., 2 vols., New York, Dover Publications, 1957 [1. ${ }^{\mathrm{a}}$ ed., 1892], vol. I, pp. 662b-664a.

20 Vid. José de VAlDIVIELSo, op. cit., pp. XXXVII-XXXVIII de la «Introducción».

21 Vid. Ricardo del ARCO, «Escritores conceptistas del siglo XVII. Precedentes. Alonso de Ledesma y Buitrago. Alonso de Bonilla», en op. cit., p. 714.

22 Sobre la autenticidad y la justificación de estas apostillas, vid. Alonso de LEDESMA, Conceptos espirituales y morales, edición preparada por Francisco AlMAGRO (Biblioteca de visionarios, heterodoxos y marginados, vol. 24), Madrid, Editora Nacional, 1978; dice el editor en la p. 26: «Las notas a los poemas, a pie de página se encuentran en la edición de 1612, que es la que hemos utilizado, pareciendo casi eviden- 
definiciones de las palabras «terrero» $\mathrm{y}$ «sacre» que las he buscado yo en el Tesoro... de Covarrubias y en el Diccionario de Autoridades, respectivamente:

«64) Al Santissimo SaCRamento

En Metafora de tirar al blanco

\section{Romance}

[1] EN el terrero ${ }^{23}$ de amor ha puesto la Iglesia vn blanco ${ }^{24}$, à do tirar los sentidos: mas de cinco yerran quatro.

[2] La vista tirò, y quedose su flecha en el color aluo, en el sabor, la del gusto, $y$ en el olor, la de olfato.

[3] El oydo, por no errar, dexó que tirase el tacto, y puesta en la Fee la mira, tirò, $y$ acerto en el blanco.

[4] $\mathrm{O}$ que bien que tirò amor, pues siendo el nido tan alto, acertò al sacre ${ }^{25}$ del Verbo, $\mathrm{y}$ baxò herido acà baxo.

tes que son notas del propio autor; pero por su evidente ramplonería explicativa en muchos de sus casos, cuando no la falta total de sentido explicativo, nos hacen dudar mucho de que pertenezcan a él, y en esta seguridad han sido omitidas por nuestra parte, siendo por otra parte claro que si hubiesen sido debidas al autor han sido con seguridad añadidas de una manera externa y quizás para salvar escollos de censura; sabido es que el enfrentamiento fundamental con el luteranismo acabó siendo, en cuanto a la Biblia, no otro que éste sobre las notas explicativas al texto. Parece, pues, que las notas de los conceptos no son otra cosa que un vulgar simulacro en ese contexto y que para un lector de hoy carecen de todo interés.»

23 No hallo la palabra «Terrero» en el Tesoro... de CovARRUBIAS. Entre las varias acepciones de la voz «Terrero» que da la REAL ACADEMIA ESPAÑOLA, en op. cit., vol. 3 , p. 259 b de la segunda numeración, creo que la más adecuada para el presente trabajo es la siguiente: «TERRERO. Se toma también por el objeto, o blanco, que se pone para tirar a él, y se usa en sentido metaphórico. Llámase assí por el sitio donde se pone, que, para que no rechace la bala, se forma regularmente de tierra.»

24 «Hostia.»

25 Vid. Sebastián de CovarRubias, op. cit., p. 919a: «SACRE. Especie de halcón.» El Diccionario de Autoridades, vol. 3, p. $12 \mathrm{~b}$ de la segunda numeración, trae información más satisfactoria para este trabajo: «SACRE. [...] Especie de halcón. [...] Unos le deducen del arábigo Sacrón, y otros del latino Sacer, fundados en llamarle ave sagrada.» Cfr. con el verso 18 que dice «caçaréys al sacre Sacro.» 
[5] Tiralde vos, alma mía, caçareys al sacre Sacro, haziendo la punteria, donde la Fee os ha enseñado.

[6] Las cuerdas del coraçon torced contricion, en tanto que doblo la voluntad, hasta hazer della vn buen $\operatorname{arco}^{26}$.

[7] Templad la cuerda abstinencia ${ }^{27}$ poned la mirada recato ${ }^{28}$, preuenid dolor las flechas ${ }^{29}$, alçad oracion los braços ${ }^{30}$.

[8] Cerrar el ojo desseo a los deleytes humanos ${ }^{31}$, y abrid solo el de la $\mathrm{Fee}^{32}$ hareys vn tiro acertado.

[9] No os faltarà que tirar à la Hostia deste blanco ${ }^{33}$, ò al Aue de aquesta caça, que es lo mismo (bien mirado).

[10] Lagrimas tiren los ojos, suspiros el pecho casto, desseos el coraçon,

y buenas obras las manos ${ }^{34}$.

[11] Y por si el arco de gracia por la cuerda salta à caso ${ }^{35}$, (que la persona mas cuerda viene à quebrar en pecado).

Prestadme amor el arco,

Porque la Fee me enseña à tirar largo» ${ }^{36}$.

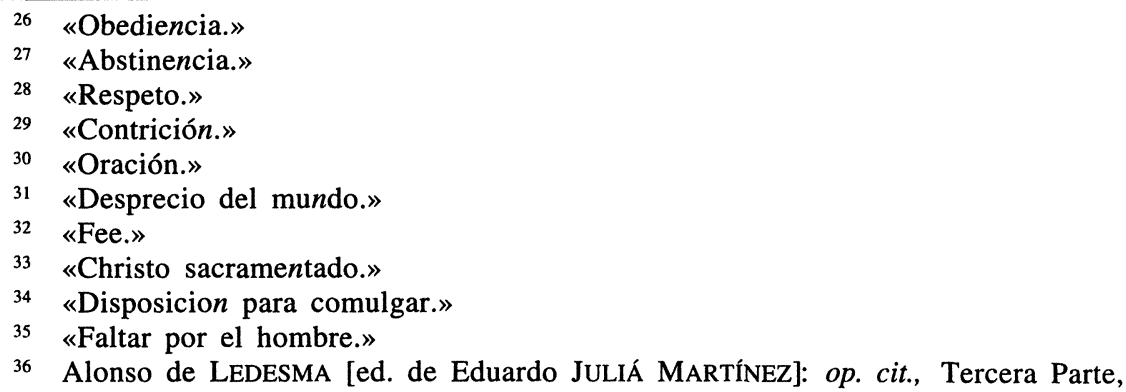


Este romance de Ledesma, sobre todo en sus tres primeras estrofas, ofrece una popularización del himno «Adoro Te devote, latens Deitas» ${ }^{37}$ de Santo Tomás de Aquino, en el siguiente fragmento:

«Visus, tactus, gustus in te fallitur,

Sed auditu solo tuto creditur:

Credo quidquid dixit Dei Filius:

Nil hoc verbo veritatis verius» ${ }^{38}$.

De todos los sentidos del cuerpo humano (cfr. con el v. 4 del romance de Ledesma), aquí se contempla cómo el del oído es el único asociado al concepto de la fe (cfr. con los vv. 9-12). El cristianismo es una religión de la palabra revelada; en la tradición judeocristiana, el cristiano tiene conocimiento sensible de Dios por haber escuchado su palabra, en contraposición, por ejemplo, a la tradición griega, más proclive al sentido de la vista en la percepción de los cánones, de las formas y de la belleza.

\section{A GUISA DE EPÍlOGO}

Por último, en relación al «concepto» hay que tener en cuenta, que no debe ser considerado aquí como una simple pirueta intelectual, sino como un esfuerzo aglutinador (desde el ámbito de la literatura y de las ideas, si se quiere, pero no por ello con menos aplicación práctica) que tiende a unificar fragmentos de un mundo caótico, como es la sociedad barroca desde principios del siglo XVII. La historia nos enseña que, en las épocas de grandes crisis, siempre ha surgido una idea, un movimiento, una tendencia, ya sea cultural, artística, estética, etc., que ha reaccionado contra el desorden y ha actuado como elemento de cohesión para superar las crisis, o, al menos, disimularlas, y volver así a la estabilidad y a la armonía. No hace falta aportar pruebas del desorden barroco, de su angustia vital y su desengaño, que son visibles en la pintura y perceptibles en la literatura y pensamiento de la época. En el barroco se ha roto la armonía renacentista o se ha hiperbolizado, que es lo mismo, y, en cualquier caso, se necesitan muchos puntos de referencia para recuperarla, y creo que uno de esos puntos es el «concepto», y su hija intelectual, la «agudeza», que se precisa para exponerlo y divulgarlo. Esto ha sido señalado por estudiosos de la literatura en relación a la obra de Gracián ${ }^{39}$ y a las constantes intelectuales que

37 Vid. J[ohn] J[ULIAN]: «Adoro Te devote, latens Deitas» en op. cit., vol. I, pp. 22a-23b.

38 Vid. el Liber Usualis Missa et Officii pro Dominicis et Festis cum Cantu Gregoriano, Tournai, Desclée \& Co, 1953, p. 1855.

39 Vid. estos dos trabajos de T. E. MAY, «Gracián's Idea of the Concepto», en Hispanic Review, XVIII (1950), pp. 15-41, y «An Interpretation of Gracián's Agudeza y arte de ingenio», en ibídem, XVI (1948), pp. 275-300. Ambos trabajos citados por J. M. AguirRe en José de VAlDivielso, op. cit., p. L, nota 46 de la «Introducción». 
la animan, pero, además, este párrafo de J. M. Aguirre me parece muy interesante y merece la pena citarlo:

«[...] las distintas expresiones artísticas de la época [...] pienso que [...] poseen un fundamento común, el cual podría, tal vez, justificarse admitiendo que el barroco es, por decirlo con cierta fuerza, omnívoro, que se apodera de todo tipo de experiencias y que lo hace mediante «actos del entendimiento» que relacionan unas con otras; el concepto, con su tendencia a hallar analogías, o correspondencias, entre las realidades y objetos más dispares, puede entenderse como un intento de encontrar el hilo que une las partes de un mundo en descomposición, de encontrar un cierto tipo de unidad allí donde el entendimiento, sin la agudeza, sólo puede ver fragmentos; el barroco es un esfuerzo casi desesperado por conservar la unidad intelectual y religiosa de la época anterior; el concepto y la alegoría están, pues, sirviendo necesidades sociales y espirituales muy importantes» ${ }^{40}$.

Creo que está muy clara la enorme importancia del concepto y la alegoría en la vida espiritual de la época. He podido comprobar perfectamente esta importancia en textos de villancicos y romances de Pujol, de otros compositores y de los inevitables anónimos, todos contemporáneos al maestro mataronés. Y, aún más, Joaquín Casalduero, a partir de La vida es sueño, resalta la trascendencia del concepto, tal y como es vivido y sentido en el Barroco, y lo eleva a la categoría de postura vital:

"Clotaldo nos muestra que la actitud del di[s]currir en el Barroco español no es intelectual, sino sentimental. La verdad no hemos de buscarla, hemos de apoderarnos sentimentalmente de ella. A Don Juan le dirán que hay Dios, Muerte e Infierno; a Segismundo la [sic] advertirán que la vida es sueño. Engañado por la temporalidad, el primero desoye el aviso, se condena; Segismundo se apodera de la advertencia, la hace suya y se salva. El discurrir no es en el Barroco católico español un acto intelectual, sino vital» ${ }^{41}$.

Los presentes apuntes han pretendido sólo dar inicio al tema que, por otra parte, se muestra sugestivo y digno de estudiarse con mayor detenimiento y profundidad.

40 Ibídem, p. LXI.

41 Joaquín CASALDUERo: Estudios sobre el teatro español, Madrid, 1972, 3. a ed., p. 170 s., apud Gabriel GonZÁleZ, Drama y teología en el siglo de oro, Salamanca, Ediciones Universidad de Salamanca, 1987, p. 56, nota 137. 


\section{BIBLIOGRAFÍA}

ARCO, Ricardo del, «Baltasar Gracián y los escritores conceptistas del siglo XVII», en Historia general de las literaturas hispánicas, publicada bajo la dirección de D. Guillermo DíAZ PLAJA, con una introducción de D. Ramón MENÉNDEZ PIDAL, vol. III «Renacimiento y Barroco», Barcelona, Editorial Barna, S.A., 1953, pp. 693-726.

-, «Escritores conceptistas del siglo XVII. Precedentes. Alonso de Ledesma y Buitrago. Alonso de Bonilla», en op. cit., pp. 713-715.

BARTHES, Roland: El placer del texto, Buenos Aires, Siglo XXI Argentina, 1974 (1. ${ }^{\mathrm{a}}$ ed. española).

CASALDUERO, Joaquín: Estudios sobre el teatro español, Madrid, 1972, (3. ${ }^{\text {a }}$ ed).

Covarrubias, Sebastián de: Tesoro de la Lengua Castellana o Española, según la impresión de 1611, con las adiciones de Benito Remigio Noydens publicadas en la de 1674, edición preparada por Martín de RIQUER, Barcelona, S. A. Horta, I. E., 1943.

FERRATER MORA, José: Diccionario de filosofía, Madrid, Alianza Editorial, 1979, 4 vols.

GONZÁLEZ, Gabriel: Drama y teología en el siglo de oro, Salamanca, Ediciones Universidad de Salamanca, 1987.

GRACIÁN, Baltasar: Agudeza y arte de ingenio, edición, introducción y notas de Evaristo CORREA CALDERón, Madrid, Editorial Castalia, 1969, 2 vols.

J[ULIAN], J[ohn]: «Lauda Sion Salvatorem» en A Dictionary of Hymnology, Edited by John Julian, D.D., 2 vols., New York, Dover Publications, 1957 [1. ${ }^{a}$ ed., 1892], vol. I, pp. 662b-664a.

—, «Adoro Te devote, latens Deitas» en op. cit., vol. I, pp. 22a-23b.

Lambea Castro, Mariano: Los villancicos de Joan Pau Pujol $(* 1570-+1626)$. Contribución al estudio del villancico en Cataluña, en el primer tercio del siglo XVII, [Edición en microficha] volumen I (Estudio), Bellaterra, Publicacions de la Universitat Autònoma de Barcelona, 1998.

LEDESMA, Alonso de: Conceptos Espirituales y Morales, edición, introducción y notas de Eduardo JUliá MARTíneZ (Biblioteca de Antiguos Libros Hispánicos, A, XXVII, XXVIII y XXIX), Madrid, Consejo Superior de Investigaciones Científicas, Instituto «Miguel de Cervantes», 1969, 3 vols.

-, Conceptos espirituales y morales, edición preparada por Francisco ALMAGRo (Biblioteca de visionarios, heterodoxos y marginados, vol. 24), Madrid, Editora Nacional, 1978

Liber Usualis Missa et Officii pro Dominicis et Festis cum Cantu Gregoriano, Tournai, Desclée \& Co, 1953

MAY, T. E.: «Gracián's Idea of the Concepto», en Hispanic Review, XVIII (1950), pp. $15-41$

-, «An Interpretation of Gracián's Agudeza y arte de ingenio», en Hispanic Review, XVI (1948), pp. 275-300.

Música y Literatura en la Península Ibérica: 1600-1750, Actas del Congreso Internacional (Valladolid, 20-21 y 22 de febrero de 1995), edición a cargo de María Antonia VIRGILI BLANQUET, Germán VEgA GARCÍA-LuENGos y Carmelo CABALLERo FERNÁNDEZ-RUFETE, Valladolid, V Centenario Tratado de Tordesillas, 1997.

Pujol, Joan: Amor pone cerco a Dios, Manuscrito musical de la Biblioteca de Catalunya, sign.: M. 749/2.

-, Al blanco que está Dios allí, Manuscrito musical de la Biblioteca de Catalunya, sign.: M. 749/14.

Real ACADEMIa EsPañola, Diccionario de Autoridades (Biblioteca Románica Hispánica, V. Diccionarios, 3), (edición facsímil del Diccionario de la lengua castella- 
na..., Madrid, Imprenta de la Real Academia Española, 1737), Madrid, Editorial Gredos, 1976, 3 vols. (3. ${ }^{a}$ reimpr.).

SIMÓN DíAZ, José: Bibliografía de la literatura hispánica, Tomo XIII, Madrid, Consejo Superior de Investigaciones Científicas, Instituto «Miguel de Cervantes» de Filología Hispánica, 1984.

VAldivielso, José de: Romancero espiritual, edición, introducción y notas de J. M. AguirRe, Clásicos Castellanos, 228, Madrid, Espasa-Calpe, 1984. 
Rntrada solo Cantus Pus A4

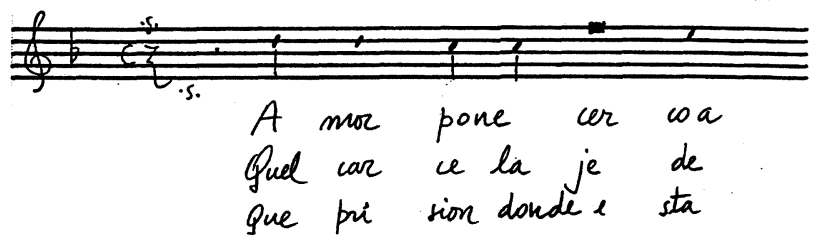

Cantus $2 \mathrm { g. } 1 4 \longdiv { \text { Que } }$

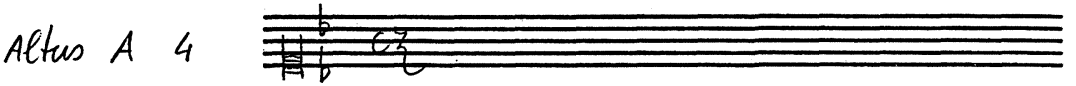

Bassies [sic] a 4

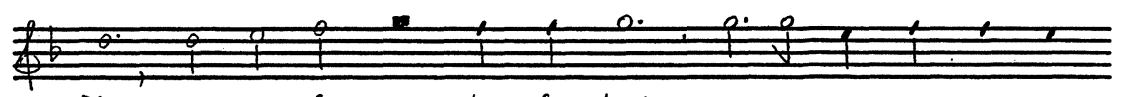

Dios, no se lei ra por los hies,

Dios, pa ra $i$ so

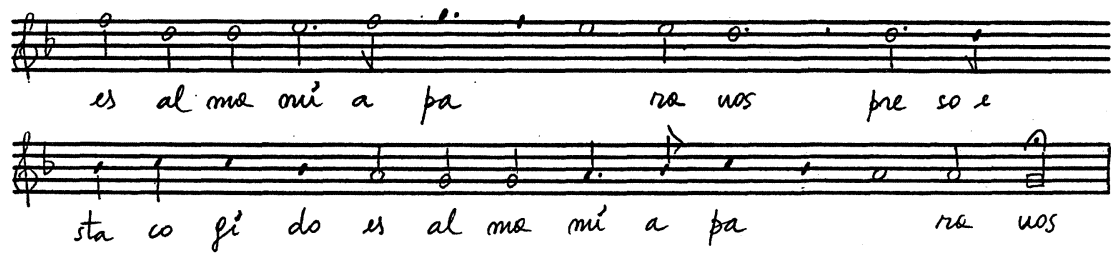

A 4
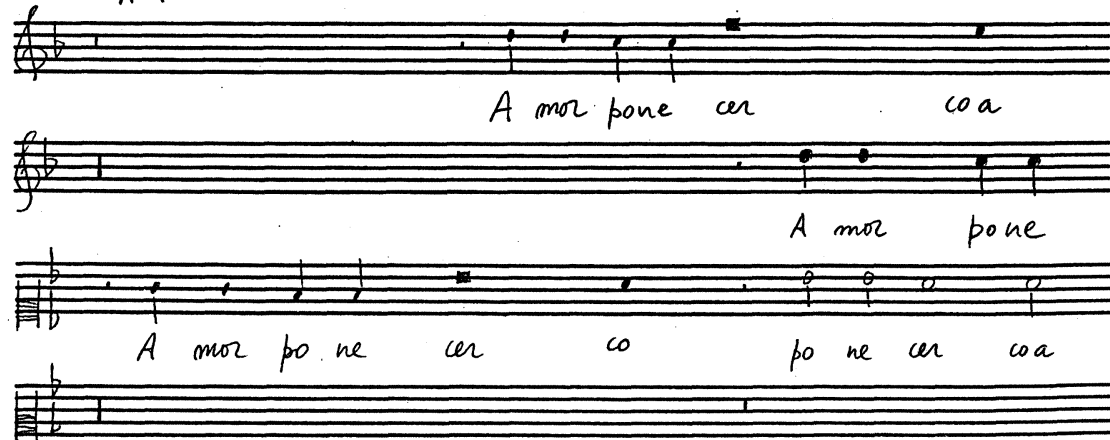

FIG. 1.-Joan Pujol, Amor pone cerco a Dios, Biblioteca de Catalunya, sign.: M. 749/2 (Transcripción paleográfica: Mariano Lambea). 

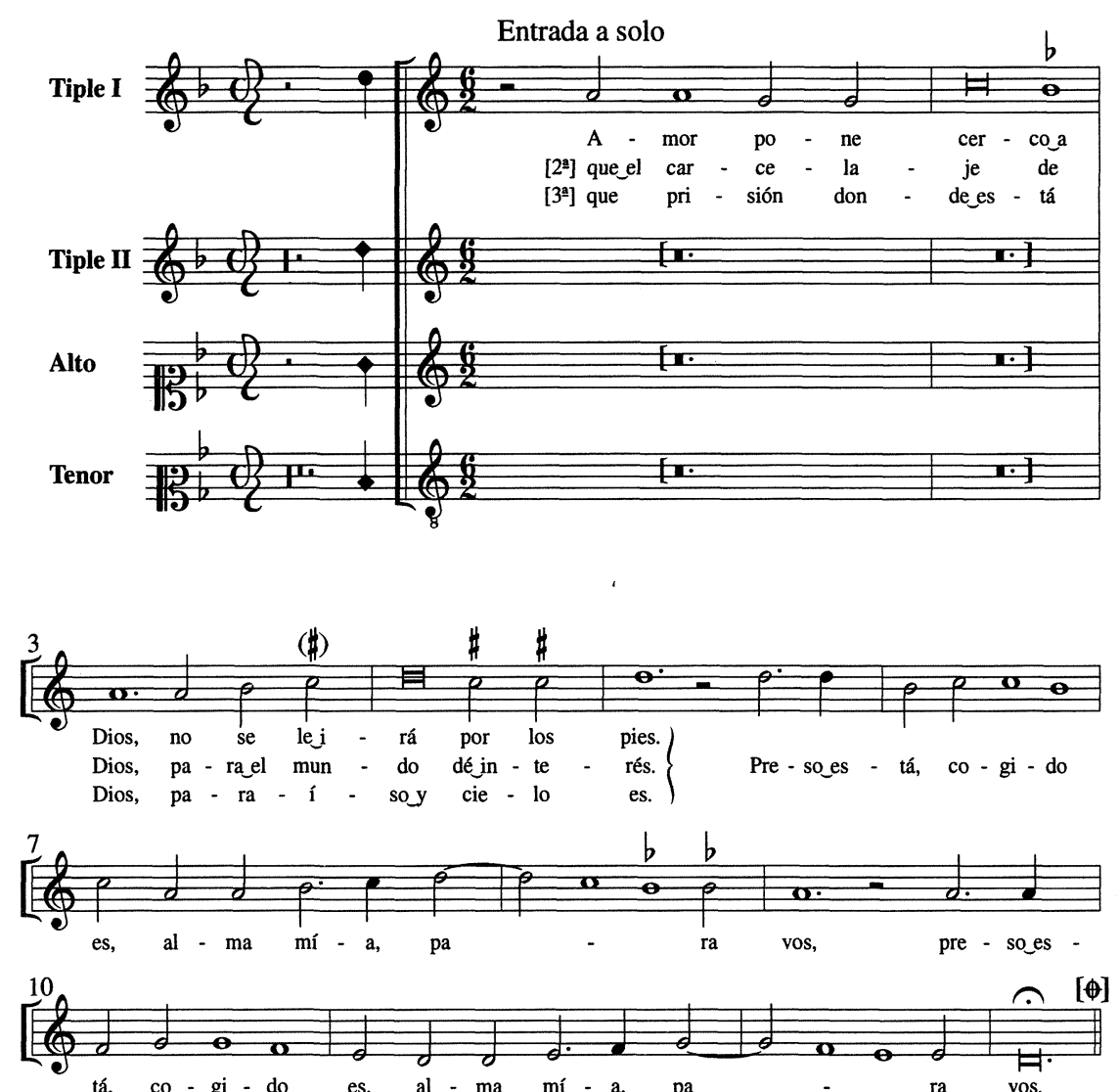

tá, co - gi - do es, al - ma mí - a, pa

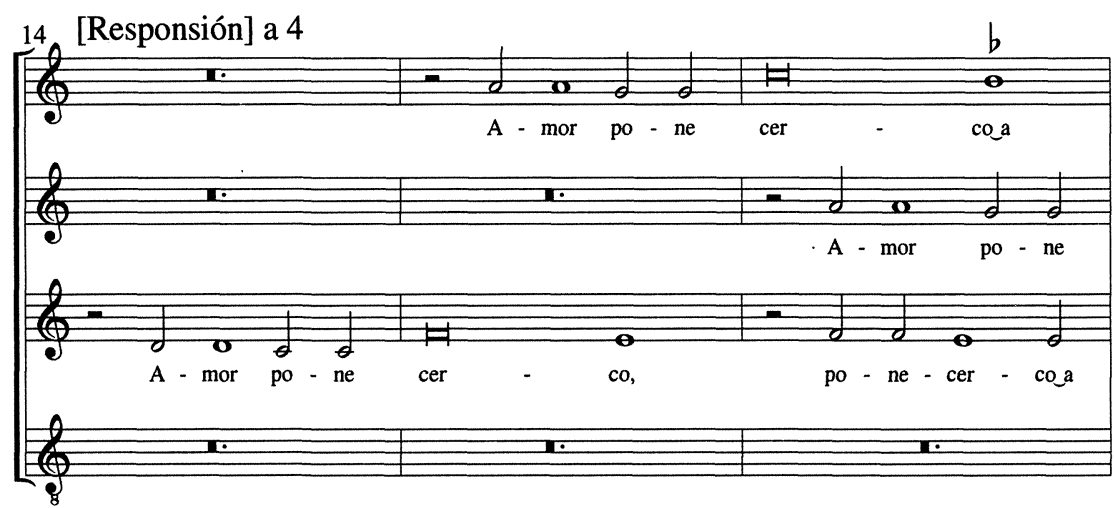

FIG. 2.-Joan Pujol, Amor pone cerco a Dios, Biblioteca de Catalunya, sign.: M. 749/2 (Edición diplomático-interpretativa en notación moderna: Mariano Lambea). 

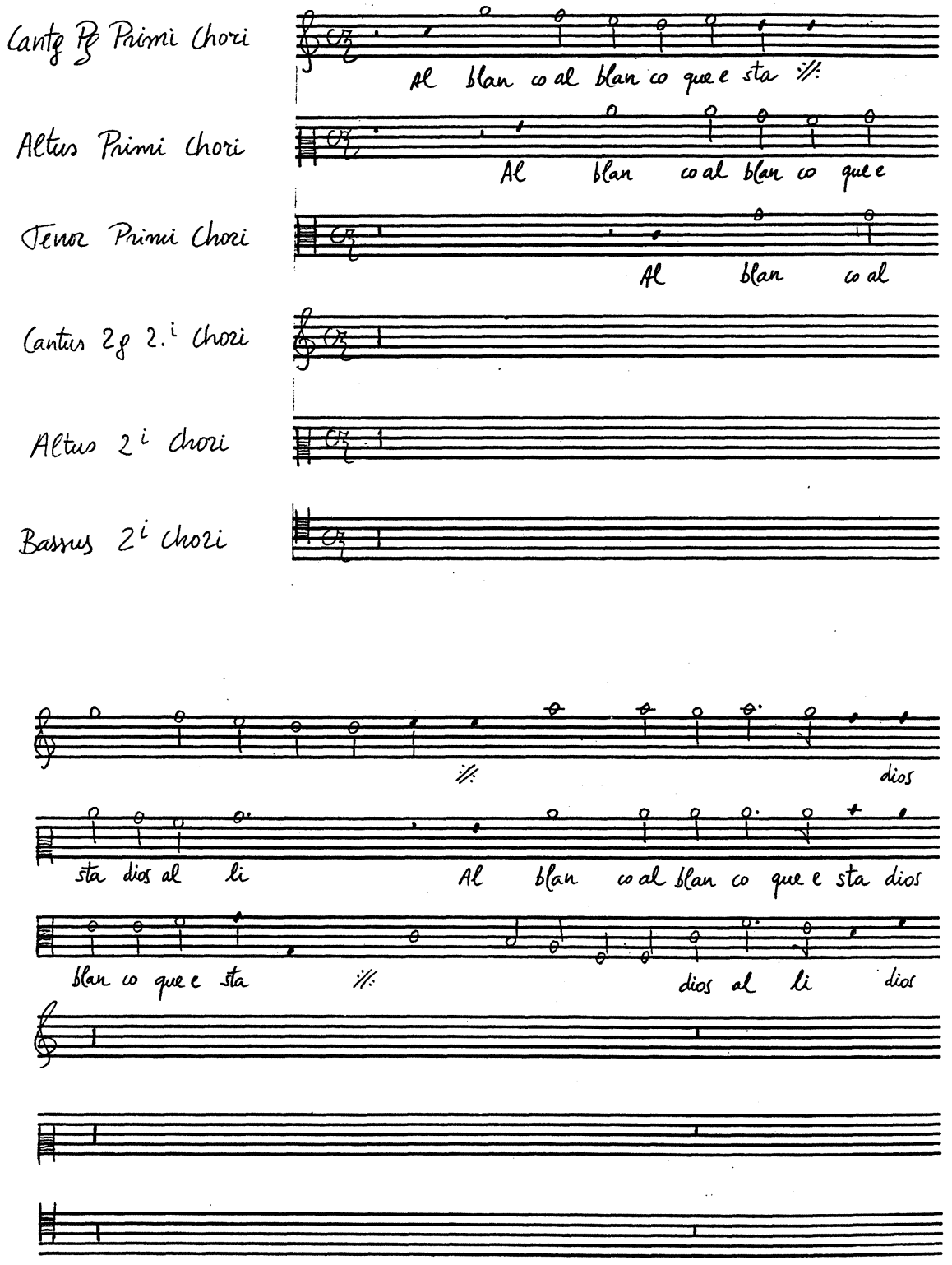

FIG. 3.-Joan Pujol, Al blanco, que está Dios allí, Biblioteca de Catalunya, sign.: M. $749 / 14$ (Transcripción paleográfica: Mariano Lambea). 

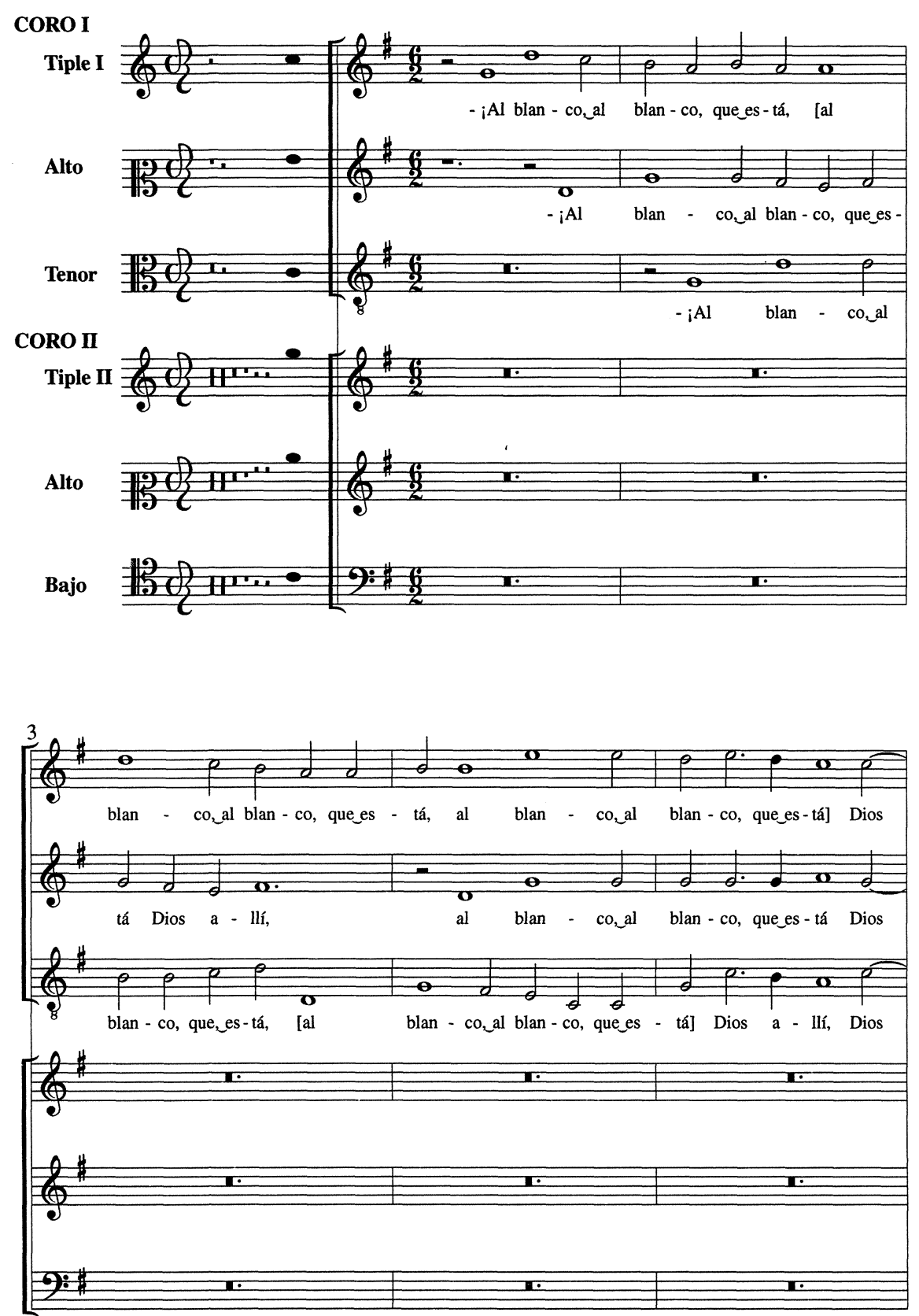

FIG. 4.-Joan Pujol, Al blanco, que está Dios allí, Biblioteca de Catalunya, sign.: M. 749/14 (Edición diplomático-interpretativa en notación moderna: Mariano Lambea). 